\title{
Temporal and spatial variability of atmospheric ammonia in the Lombardy
} region (Northern Italy)

\section{Giovanni Lonati and Stefano Cernuschi}

Civil and Environmental Engineering Department, Politecnico di Milano, Italy

Corresponding author's e-mail address: giovanni.lonati@polimi.it

\begin{abstract}
This work investigates the spatial and temporal variability of atmospheric ammonia concentrations in the Lombardy region in Northern Italy, where its continuous measurement at hourly resolution began in 2007 at monitoring sites representative of three different land use areas (urban, rural, and mountain locations). Ammonia concentration data have been jointly elaborated with wind direction and speed to highlight the association between the origin of the air masses and the concentration levels observed at the monitoring sites far from the primary sources, essentially consisting of farming activities and cattle and pigs breeding located in the South-Eastern part of the Lombardy region. The annual average concentrations of ammonia observed at urban (4.4-13.4 $\mu \mathrm{g} \mathrm{m}^{-3}$ range) and rural (17-35 $\mu \mathrm{g} \mathrm{m}^{-3}$ range) monitoring sites are in substantial agreement with literature data, which are however limited and strongly influenced by the measurement techniques used. The lowest concentration levels (1.1-5.8 $\mu \mathrm{g} \mathrm{m}^{-3}$ range) are observed at the monitoring sites in the mountain areas. Both the seasonal and daily time patterns of the concentrations appear strongly related to some features of the measurement sites, namely with regard to their exposition to agricultural activities, whose seasonal practices arise in emissions responsible for strong variations in the ammonia atmospheric levels. Conversely, in the mountain areas in the North of region, weather conditions effects on atmospheric circulation seem to play a more important role than local sources, with the highest concentrations occurring when the breezes transport $\mathrm{NH}_{3}$-rich air masses from the Southern part of the region.
\end{abstract}

Keywords: Ammonia, air quality, time pattern, polar plots, Po valley

\section{Introduction}

The interest for atmospheric ammonia $\left(\mathrm{NH}_{3}\right)$ is essentially related to its fundamental role in the processes of acidification of the ecosystems and of water eutrophication, both originated by its deposition on sensitive environments (Zhang et al., 2012; Bobbink et al., 1998). Furthermore, $\mathrm{NH}_{3}$ is the main basic compound capable of neutralizing atmospheric acid gases and thus is a precursor of secondary inorganic particulate material, whose harmful human health and environmental effects are well known (Schlesinger and Cassee, 2003; Erisman and Schaap, 2004; Sutton et al., 2009). $\mathrm{NH}_{3}$ can react with sulphur dioxide $\left(\mathrm{SO}_{2}\right)$ and nitrogen oxides (NOx) to form ammonium sulphate $\left(\left(\mathrm{NH}_{4}\right)_{2} \mathrm{SO}_{4}\right)$, ammonium bisulphate $\left(\mathrm{NH}_{4} \mathrm{HSO}_{4}\right)$, and ammonium nitrate $\left(\mathrm{NH}_{4} \mathrm{NO}_{3}\right)$, significantly contributing to the presence of fine particle mass (PM2.5) in ambient air and with relevant implications for human health (Brunekreef and Holgate, 2002), for atmospheric visibility and for global radiation budgets (Clarisse et al., 2009; Horvath, 1992; Sutton et al., 1994). Modeling simulations (Heald et al., 2012; Schiferl et al., 2014) and air quality monitoring data (Gong et al., 2013) confirmed the specific role of $\mathrm{NH}_{3}$ in the formation of secondary inorganic aerosol, with negative effects on both climate and air quality (Erisman et al., 2013; Paulot and Jacob, 2014). In spite of its environmental significance, atmospheric $\mathrm{NH}_{3}$ still receives little attention and is not subject to air quality standards. In the European Union, despite atmospheric emission limits are fixed only for very few sources, such as waste incinerators and combustion processes where $\mathrm{NH}_{3}$ is used in both catalytic and non-catalytic processes for $\mathrm{NOx}$ emission control, national $\mathrm{NH}_{3}$ emission reduction commitments for 
Member States are set by the National Emission Ceilings Directive for 2020 and 2030 (EU Directive 2016/2284/EU).

At the global scale $\mathrm{NH}_{3}$ emissions have more than doubled since pre-industrial times because of both agricultural intensification and widespread use of fertilizer (Galloway et al., 2003). Actually, agricultural and livestock activities represent the largest and almost exclusive $\mathrm{NH}_{3}$ source (Warner et al., 2016); people and traffic emissions may have an impact only in the nonagricultural regions, as suggested by the higher $\mathrm{NH}_{3}$ ambient levels found in densely populated areas (Suh et al., 1995). In the United States more than $82 \%$ of $\mathrm{NH}_{3}$ emissions are attributable to the agricultural sector (US EPA National Emission Inventory, 2014) with a growing trend due to the combined effect of the increase of farming and animal husbandry and the use of nitrogen fertilizers. In the European Union, the agricultural sector is responsible for more than 94\% of $\mathrm{NH}_{3}$ emissions (EEA, 2017), with the limitations on the use of synthetic nitrogen fertilizers and the improvement of practices in the management of livestock waste leading to a slight emission reduction in recent past years. However, increasing ambient concentration trends for $\mathrm{NH}_{3}$ have been estimated around $2.6 \% \mathrm{yr}^{-1}$ over the US, $1.8 \% \mathrm{yr}^{-1}$ over the European Union and $2.3 \% \mathrm{yr}^{-1}$ over China (Warner et al., 2017), also following to the progressive decrease of acid gases in the atmosphere, in particular $\mathrm{SO}_{2}$, whose neutralization is an important pathway for the removal of ammonia.

Because of the combination of unfavourable morphology and climatology of the area and of high density of emission sources, the river Po valley in Northern Italy is one of the most critical areas in Europe for air quality issues, including ammonia concentration levels, making it one of the main $\mathrm{NH}_{3}$ hot-spots worldwide (Figure 1, left panel). In particular, since also in the Lombardy region $\mathrm{NH}_{3}$ emissions derive almost exclusively from agriculture, the major concern for atmospheric $\mathrm{NH}_{3}$ is in the southernmost portion of the regional area, due to the high emission levels determined by the local agricultural and animal breeding activities (Figure 1, right panel).

According to the emission inventory of the Lombardy region (BIBLIO), 97.7\% of the $\mathrm{NH}_{3}$ annual emissions (about 101800 tons per year) derive from agricultural activities, mostly from liquid and solid manure management (about 90\%), followed by fertilizer use (10\%). The other sectors responsible for appreciable $\mathrm{NH}_{3}$ emissions are road transport (1\%), waste treatment and disposal $(0.5 \%)$, combustion in manufacturing industry $(0.4 \%)$, and non-industrial combustion plants $(0.2 \%)$.

Focusing on the Lombardy region, where for almost 15 years the air quality monitoring network has been continuously collecting ambient $\mathrm{NH}_{3}$ data, this work analyses the spatial variability and temporal evolution of its concentration levels, as well as the relationship between monitored values and local winds regime (speed and direction), in order to investigate the origin of emission sources that determine the most relevant impacts on air quality.

\section{Materials and methods}

\section{1. $\mathrm{NH}_{3}$ monitoring network in Lombardy}

The air quality monitoring network operated by the Environmental Agency (ARPA) of the Lombardy region has begun to continuously collect data for atmospheric $\mathrm{NH}_{3}$ at four sites in 2007. Progressively, the monitoring network has been expanded and atmospheric $\mathrm{NH}_{3}$ is currently measured at 11 stations, distributed over almost all the region at representative sites for air quality assessment, with very good annual data availability (generally more than $80 \%$ on annual basis).

$\mathrm{NH}_{3}$ concentrations are measured at hourly resolution with instruments based on the chemiluminescence technique that enables $\mathrm{NH}_{3}$ measurement indirectly. The technique involves a sequential process with the catalytic transformation to $\mathrm{NO}$ of all the nitrogen compounds ( $\mathrm{NO}, \mathrm{NO}_{2}$, and $\mathrm{NH}_{3}$ ) present in the air sample and the subsequent evaluation of 
total nitrogen $\mathrm{N}_{\mathrm{t}}$ (expressed as $\mathrm{NO}$ ); the concurrent separate measurements of both $\mathrm{NO}$ and $\mathrm{NO}_{2}$ (still expressed as NO) let $\mathrm{NH}_{3}$ to be obtained by difference. Such analytical determination is however complex and the final $\mathrm{NH}_{3}$ ammonia may be inaccurate just because of the critical issues of the chemiluminescence technique (Villena et al., 2012; Dunlea et al., 2007) as related to the catalytic conversion efficiencies of the various compounds, in particular for $\mathrm{NH}_{3}$ oxidation to NO (Capiaghi et al., 2014).

\section{2. $\mathrm{NH}_{3}$ datasets}

In this work $\mathrm{NH}_{3}$ data from 12 monitoring sites collected between 2007 and 2019 have been analyzed (Figure 2). Sites have been grouped together in three areas (urban, rural and mountain), according to the classification criteria adopted by ARPA for air quality monitoring sites. In particular, the urban group (sites S1-S5) includes the two sites in the city of Cremona (360000 inhab.), those in the metropolitan area of Milan (3200000 inhab.), and the site in the city of Pavia (70000 inhab.). In Cremona the monitoring sites are located North-Eastern of the city centre (S1-CR Fatebenefratelli), and on the outskirts of the city (S2-CR Gerre Borghi), close to the banks of the Po river and potentially more exposed to the emissions generated in the surrounding countryside. In the metropolitan area of Milan sites are located in the heart of the city park of Monza (S3-Monza Parco), not directly exposed to emission sources, and at an urban background site in the university area of Milan (S4-MI Pascal). In Pavia the monitoring site is located at the entrance of the city park North of the city centre (S5-Pavia-Folperti). The monitoring sites of the rural group (S6-S10) are all located in the Southern part of the region. In particular, S6-Corte de' Cortesi and S8-Bertonico sites are positioned in an area directly interested by emissions of agricultural and livestock activities. Actually, S6 site is in a fairly isolated location, far from roads and industrial activities, but immediately near to a pig farm; S7 and S8 sites are in areas devoted to agricultural (cereals and fodder production) and livestock activities (beef and dairy cattle and pigs). The mountain group includes the sites of Colico (S11) and Moggio (S12). S11-Colico site is located in the last town on the Eastern shore of the Lake of Como, at about $250 \mathrm{~m}$ a.s.l., in a position where it is not exposed to ammonia sources but may be somewhat affected by transport phenomena of pollutants emitted in the plain area of the region, arising from the cyclic circulation of air masses that go up the Lake Como daily. Conversely, S12-Moggio site is really in a mountain area at about $1200 \mathrm{~m}$ a.s.l. in Valsassina valley, a pre-alpine area where there are no significant emission sources of ammonia. Nevertheless, as for S11 site, air masses coming from the plain, located to the South, can be channeled in the valley and reach the site, potentially affecting local air quality.

Wind speed and wind direction data used for bivariate analyses for investigating the relationship between $\mathrm{NH}_{3}$ concentrations and local anemological regime, when not concurrently available at the air quality monitoring sites, have been taken from the nearest meteorological stations, as shown in Figure 2.

\section{Results}

\section{1. $\mathrm{NH}_{3}$ concentration levels}

The mean and min-max range of $\mathrm{NH}_{3}$ annual average concentrations monitored and available for the study are summarized in Table 1. The sites of the urban group show rather similar concentration levels: mean values are mostly in the 7-10 $\mathrm{g} \mathrm{m} \mathrm{m}^{-3}$ range, whilst the minimum and maximum values are in the 4-8 $\mathrm{g} \mathrm{m} \mathrm{m}^{-3}$ range and in the $10-13.5 \mu \mathrm{g} \mathrm{m}^{-3}$ range, respectively. Slightly higher levels are observed at S2-CR Gerre Borghi (mean $14.4 \mu \mathrm{g} \mathrm{m}^{-3}$; range 8.2-21.3 $\mu \mathrm{g} \mathrm{m}^{-3}$ ), attributable to the outskirt location of the station that makes the site more exposed to the emissions from agricultural activities in the surrounding areas. The urban sites, mostly located in urban background environments and not directly exposed to primary emissions, show significantly lower concentrations than those observed at the rural sites, particularly for those located in areas with strong agricultural and animal husbandry activities (S6-Corte de' Cortesi 
and S8-Bertonico). At these sites the annual average concentrations vary from a minimum of $21.9 \mu \mathrm{g} \mathrm{m}^{-3}$ to a maximum of $81.7 \mu \mathrm{g} \mathrm{m}^{-3}$, with mean values of $30.1 \mu \mathrm{g} \mathrm{m}^{-3}$ at S8-Bertonico and 53.1 $\mu \mathrm{g} \mathrm{m}^{-3}$ at S6-Corte de' Cortesi. At the other three rural sites (S7, S9, and S10) $\mathrm{NH}_{3}$ levels are between those detected at urban and rural sites. Actually, at site S7-Piadena, where monitoring took place in 2013-2014 only, and at site S9-Schivenoglia concentrations are more similar to those of the suburban S2-CR Gerre Borghi site, ranging between $11.3 \mu \mathrm{g} \mathrm{m}^{-3}$ and $23.5 \mu \mathrm{g} \mathrm{m}^{-3}$ and with mean values of $20.6 \mu \mathrm{g} \mathrm{m}^{-3}$ and $16.2 \mu \mathrm{g} \mathrm{m}^{-3}$, respectively. Conversely, $\mathrm{NH}_{3}$ values at S10-Sannazzaro site have essentially the same levels of the urban sites, both in terms of the concentration range $\left(7.4-9.9 \mu \mathrm{g} \mathrm{m}^{-3}\right)$ of mean values $\left(8.4 \mu \mathrm{g} \mathrm{m}^{-3}\right)$.

The annual values observed at S6 site (38.3-81.7 $\left.\mu \mathrm{g} \mathrm{m}^{-3}\right)$, practically twice as high as those of sites S2, S7, S9, and even S8 (21.9-35.8 $\left.\mu \mathrm{g} \mathrm{m}^{-3}\right)$, point out the impact of the pig farm located at less than $100 \mathrm{~m}$ from the site itself: thus, data from this site cannot be considered representative of an area with a generic rural vocation but of the local impact on $\mathrm{NH}_{3}$ of a very specific emission source. On the other hand, the lower values observed at S9 and especially at S10 site suggest that, despite their location in rural portions of the Lombardy plain, they are positioned in areas with less intensive agricultural utilization and far from direct emission sources. Nevertheless, data from S2 site show that even at suburban sites the influence of agricultural activities nearby can increase $\mathrm{NH}_{3}$ levels compared with downtown urban sites.

The two sites of the mountain group display the lowest annual average concentrations, between $1.1 \mu \mathrm{g} \mathrm{m}^{-3}$ and $5.8 \mu \mathrm{g} \mathrm{m}^{-3}$, with maximum values substantially similar to the minimum values of the concentration range at the urban sites. Annual average concentrations are in the orders of a few $\mu \mathrm{g} \mathrm{m}^{-3}$, namely $4.4 \mu \mathrm{g} \mathrm{m}^{-3}$ at S11-Colico and 3.4 $\mu \mathrm{g} \mathrm{m}^{-3}$ at S12-Moggio. Due to their geographical position, especially for the $S 12$ site, located in an area not densely populated at relatively high altitude, the measured values can therefore be considered representative of the background level of ammonia in Lombardy.

The annual average levels measured at the sites are essentially in agreement with literature data, although the comparison is purely indicative as the methods of measurement, the temporal resolution and frequency of measurements may differ also noticeably (Wang et al., 2015). Nevertheless, especially for the urban sites of Lombardy, $\mathrm{NH}_{3}$ levels are comparable with those of other urban sites, such as $5.4 \mu \mathrm{g} \mathrm{m}^{-3}$ reported for Seoul in South Korea (Phan et al., 2013) and $15.9 \mu \mathrm{g} \mathrm{m}^{-3}$ for Beijing in China (Meng et al., 2011). A substantial agreement is also observed for the rural sites, except for the S6-Corte de' Cortesi site, whose specificity has already been discussed. As for the sites in this study, both relatively low values, in the orders of 4-6 $\mu \mathrm{g} \mathrm{m}^{-3}$ (Wang et al., 2015; Zbieranowski and Aherne 2013; Meng et al., 2011) as at S10 site, and higher values, in the orders of 14-22 $\mu \mathrm{g} \mathrm{m}^{-3}$ (Erisman et al., 2001, Shen et al., 2011) as at sites S7, S8, and S9, are reported in the literature for rural sites worldwide.

\section{2. $\mathrm{NH}_{3}$ concentration time patterns}

The time patterns of the annual average concentrations at the monitoring sites over the study period are presented in Figure 3 (rural sites and the suburban S2 site) and in Figure 4 (urban sites, site S10, and mountain sites). At the rural sites the time patterns show irregular trends. At site S6 after an initial increasing trend that has led to the maximum annual average of $81.7 \mu \mathrm{g}$ $\mathrm{m}^{-3}$ in 2012, the annual values display a strongly decrease in 2013 and 2014, down to about 45 $\mu \mathrm{g} \mathrm{m}^{-3}$, and then rather stable values, with some fluctuations in the $38-47 \mu \mathrm{g} \mathrm{m}^{-3}$ range. Conversely, at the other three sites in Figure 3 an upward trend for annual $\mathrm{NH}_{3}$ concentration is generally observed. At site S8 a fairly constant and regular increase is observed from 2012 on, with the annual average concentration rising from about $20 \mu \mathrm{g} \mathrm{m}^{-3}$ up to $30 \mu \mathrm{g} \mathrm{m}^{-3}$ ). At sites S2 and S9 the time pattern, although less regular, still displays increasing annual average values from about $10 \mu \mathrm{g} \mathrm{m}^{-3}$ in 2013 up to about $16 \mu \mathrm{g} \mathrm{m}^{-3}$ in 2019 , but with some values in the orders of 21-22 $\mu \mathrm{g} \mathrm{m}^{-3}$ in 2017 and 2018. At the urban sites and at the rural site S10 the trends remain irregular and sometimes opposite, but with much smaller fluctuations than at the rural sites; in spite of the spread of the single annual values, overall the annual average concentrations at the 
urban sites are around $10 \mu \mathrm{g} \mathrm{m}^{-3}$ without an appreciable trend. Interestingly, even though with lower concentration levels, at site S10 the same time pattern as at the S2 and S9 sites is observed, with a progressive increase of the annual average from $4.8 \mu \mathrm{g} \mathrm{m}^{-3}$ in 2013 to $11.5 \mu \mathrm{g}$ $\mathrm{m}^{-3}$ in 2018. At the mountain sites annual average concentrations are at their lowest levels. At site S12-Moggio, during 2007-2016 values are usually within the 2.4-4.0 $\mu_{\mathrm{g} \mathrm{m}}^{-3}$, but even down to about $1.2 \mu \mathrm{g} \mathrm{m}^{-3}$ in 2012 and 2016; however, concentration levels in the last three years increase to about $5 \mu \mathrm{g} \mathrm{m}^{-3}$. On the opposite, at site $\mathrm{S} 11$, after rather stable values around $5 \mu \mathrm{g}$ $\mathrm{m}^{-3}$ in 2014-2017, lower values in the order of $3.5 \mu \mathrm{g} \mathrm{m}^{-3}$ are observed for 2018 and 2019.

Seasonal concentrations averaged over the entire study period are presented in Table 2 and summarized for different sites' groups in Figure 5. At the urban sites (S1, S3, S4, S5, and also S10) concentration levels are rather constant throughout the year, basically around $8.5 \mu \mathrm{g} \mathrm{m}^{-3}$ and slightly higher $\left(9.4 \mu \mathrm{g} \mathrm{m}^{-3}\right)$ in spring when a larger inter-site variability is also observed $\left(6.6-12.7 \mu \mathrm{g} \mathrm{m}^{-3}\right)$. At the rural sites ( $\mathrm{S} 7, \mathrm{~S} 8, \mathrm{~S} 9$, and also the suburban site $\mathrm{S} 2$ ) seasonal concentrations: i) are always higher than at the urban sites; ii) display a larger inter-site variability (in the orders of 10-15 $\mathrm{g} \mathrm{m}^{-3}$ ); iii) are basically higher during the warmest seasons, especially at site S8 and S2, even though this patterns cannot be generalized and appears strongly influenced by the local features of the site and to its exposure to the primary sources of agricultural activities. Site S6, where seasonal levels are at their highest values during the whole year because of the particular features of this site, has the same seasonal pattern of the other rural sites, with the concentration values in the $60-75 \mu \mathrm{g} \mathrm{m}^{-3}$ range in summer and autumn and down to a 40-50 $\mu \mathrm{g} \mathrm{m}^{-3}$ range in winter and spring. The two mountain sites show quite different seasonal patterns: site $\mathrm{S} 11$ is characterized by seasonal values around $5 \mu \mathrm{g} \mathrm{m}^{-3}$, with the only exception for the summer, when the concentration falls down to about $3 \mu \mathrm{g} \mathrm{m}^{-3}$. Conversely, at site S12 the concentration levels show a strong seasonal pattern, with spring and summer levels (2.7-3.5 $\left.\mathrm{g} \mathrm{m} \mathrm{m}^{-3}\right)$ about 2-3 times higher in autumn and winter (1.2-1.4 $\left.\mu \mathrm{g} \mathrm{m}^{-3}\right)$ : Actually, in the cold season, and in winter especially, hourly concentrations below the detection limit of $0.1 \mu \mathrm{g} \mathrm{m}^{-3}$ are frequently recorded. This peculiar behavior will be discussed in the following section through the joint analysis of concentration levels and wind conditions.

\subsection{Bivariate analyses}

The association between $\mathrm{NH}_{3}$ concentration levels and local anemological regimes has been investigated by means of graphic representations obtained by the joint analysis of hourly $\mathrm{NH}_{3}$ concentration and wind speed and direction data. In the resulting polar plot representations, the angle with respect to the y axis represents the direction of origin of the wind with respect to the North, the distance from the center the speed of the wind, and the color the average value of $\mathrm{NH}_{3}$ concentration detected under every wind condition recorded (Carslaw and Ropkins, 2012). Practically, the color maps let the concentration levels observed to be associated with certain wind conditions, thus providing indications on the location and distance of the emission sources that influence air quality at the monitoring site. These type of graphical representations can thus help in accounting for the presence of point sources (i.e.: large industrial complexes), pointing out those situations when they are located upwind of the monitoring site, as well as for the presence of diffuse sources homogeneously distributed around the monitoring site (i.e.: domestic heating in urban areas) when, on the other hand, there is generally no clear association between high levels of concentration and wind direction.

This last situation applies to the polar plots of this study that in general do not result in a clear effect of the wind but rather confirm the widespread nature of $\mathrm{NH}_{3}$ emissions. However, the plots highlight some specific characteristics of the different measurement sites. For the rural site $\mathrm{S} 6$, for example, in addition to a significant seasonal variability of $\mathrm{NH}_{3}$ levels, the highest concentration associated to weak winds confirm the role of the nearby pig farm as a relevant local emission source. Furthermore, the clear circular symmetry of the color plots reflects the location of the site at a point surrounded by agricultural land (Figure 6). Similar considerations 
apply to the S8 rural site, where the effect of the local source responsible for the maximum result in a circular symmetry in correspondence of weak winds (Figure 7) but they show, regardless of the season, the lowest $\mathrm{NH}_{3}$ concentration values for North-North Westerly strong winds $\left(>4 \mathrm{~m} \mathrm{~s}^{-1}\right)$ : these conditions occur during foehn episodes, actually quite unusual on an annual basis (7-10 events), which bring clean air masses from the Alps down to the plain of Lombardy, lowering the concentration levels of all the atmospheric pollutants (Mira-Salama et al., 2008). Conversely, the association of high $\mathrm{NH}_{3}$ concentration values with medium-intensity winds blowing from East to East South East in autumn suggests the transport phenomena from the Southern part of the region, where concentration levels are particularly high, towards the foothills area of the Alps. The presence of these transport phenomena is also shown in the summer plot of the mountain site S12, where the highest concentrations are observed concurrently with winds blowing from South West (Figure 8). As already reported for other pollutants (Dosio et al., 2002), the masses of air moving towards the North are channeled along the Eastern branch of Lake Como, and from there up to the Valsassina valley, bringing there the ammonia emitted from agricultural activities in the plain area of Lombardy (Supplementary Material Figure 1). In winter, this phenomenon is not so clear: on the other way, a separation is apparently observed between air masses that insist on the plain and those of the mountain area, favored also by the shallow boundary layer over the plain area (mostly with a depth of a few hundred meters only) and by the frequent phenomena of thermal inversion typical of the Po valley during the cold season. From these local conditions, site S12 displays the highest NH3 concentration in summertime and the lowest in wintertime, as shown in Figure 5.

The association between high $\mathrm{NH}_{3}$ concentrations and some wind conditions illustrated by the polar plots is further confirmed by the inspection of the conditional wind roses for hourly concentration values higher than the $90^{\text {th }}$ percentile of the entire $\mathrm{NH}_{3}$ data series (Figure 9). This analysis confirms the presence of transport phenomena of $\mathrm{NH}_{3}$-rich air masses from the Southern part of the region to the northernmost areas. In particular, for the two sites in Milan metropolitan area the highest concentrations are observed more frequently in correspondence of South-easterly winds, while in the case of S12 mountain site of Moggio for winds blowing from West-South West.

\section{Conclusions}

In Lombardy region, atmospheric $\mathrm{NH}_{3}$ levels show a marked spatial and temporal variability, with highest concentrations recorded in rural areas (annual averages in the orders of 20-80 $\mu \mathrm{g}$ $\mathrm{m}^{-3}$ ) and lowest ranges monitored at mountain sites (annual average less than $6 \mu \mathrm{g} \mathrm{m}^{-3}$ ). At urban sites, yearly average values are normally around $10 \mu \mathrm{g} \mathrm{m}^{-3}$, with a substantially stable time trend from 2007. $\mathrm{NH}_{3}$ average levels observed in Lombardy agree with literature data for similar sites, even though data are still limited and strongly influenced by the measurement techniques used.

The temporal pattern of concentrations is strongly dependent on the characteristics of the measurement sites, namely for the rural sites more directly exposed to the emissions of agricultural activities. Seasonal practices of agricultural activities determine local emissions responsible for strong variations in atmospheric $\mathrm{NH}_{3}$ concentration levels, especially in early spring and autumn. This variability, although mitigated, is also observed at the urban sites, confirming the dominant role of the emissions from agricultural and zootechnical sectors, already pointed out by emission inventories. Furthermore, the joint analysis of $\mathrm{NH}_{3}$ concentration data with local wind conditions brings out the relationships between concentration levels and the origin of air masses, showing highest concentration values occurrence in urban areas when wind breezes transport $\mathrm{NH}_{3}$-rich air masses from high emission intensity areas of the Po Valley. 


\section{References}

300

301

302

303

304

305

306

307

308

309

310

311

312

313

314

315

316

317

318

319

320

321

322

323

324

325

326

327

328

329

330

331

332

333

334

335

336

337

338

339

340

341

342

343

344

345

Bobbink, R., Hornung, M., Roelofs, J.G.M., 1998. The effects of air-borne nitrogen pollutants on species diversity in natural and semi-natural European vegetation. Journal of Ecology, 86, 717-738.

Brunekreef, B., Holgate, S.T., 2002. Air pollution and health. Lancet 360, 1233-1242.

Capiaghi, V., Pirovano, G., Colombi, C., Lonati, G., Riva, G.M., Toppetti, A., Gianelle, V., Balzarini, A., 2014. Ricostruzione modellistica dell'ammoniaca atmosferica in Pianura Padana. Proceedings of PM2014 - Sesto convegno sul particolato atmosferico, May 20-23, 2014, Genova, Italy.

Carslaw, D.C., Ropkins K., 2012, Openair - an R package for air quality data analysis. Environmental Modelling \& Software 27-28, 52-61.

Clarisse, L., Clerbaux, C., Dentener, F., Hurtmans, D., Coheur, P.-F., 2009. Global ammonia distribution derived from infrared satellite observations. Nature Geoscience 2, 479-483

Dosio, A., Galmarini, S., Graziani, G., 2002. Simulation of the circulation and related photochemical ozone dispersion in the Po plains (Northern Italy): Comparison with the observations of a measuring campaign. Journal of Geophysical Research 107, D18, 8189.

Dunlea, E.J., et al. 2007. Evaluation of nitrogen dioxide chemiluminescence monitors in a polluted urban environment. Atmospheric Chemistry and Physics 7, 2691-2704.

Erisman, J.W., Otjes, R., Hensen, A., Jongejan, P., van den Bulk, P., Khlystov, A., Möls, H., Slanina, S., 2001. Instrument development and application in studies and monitoring of ambient ammonia. Atmospheric Environment 35, 1913-1922

Erisman, J.W., Schaap, M., 2004. The need for ammonia abatement with respect to secondary PM reductions in Europe. Environmental Pollution 129, 159-163.

Erisman, J. W., Bleeker, A., Galloway, J., Sutton, M., 2007. Reduced nitrogen in ecology and the environment, Environmental Pollution 150, 140-149.

Erisman, J.W., Galloway, J.N., Seitzinger, S., Bleeker, A., Dise, N.B., Petrescu, R., Leach, A.M., de Vries, W., 2013. Consequences of human modification of the global nitrogen cycle, Philosophical Transactions of The Royal Society 368, 20130116.

European Environmental Agency 2017. European Union emission inventory report 1990-2015 under the UNECE Convention on Long-range Transboundary Air Pollution (LRTAP).

European Union (EU), 2016. Directive 2016/2284 of the European Parliament and of the Council of 14 December 2016 on the reduction of national emissions of certain atmospheric pollutants, amending Directive 2003/35/EC and repealing Directive 2001/81/EC. OJ L 344, 17.12.2016, pp. 1-31

Galloway, J.N., Aber, J.D., Erisman, J.W., Seitzinger, S.P., Howarth, R.W., Cowling, E.B., Cosby, B J., 2003. The nitrogen cascade. BioScience 53, 341-353.

Gong, L., Lewicki, R., Griffin, R.J., Tittel, F.K., Lonsdale, C.R., Stevens, R.G., Pierce, J.R., Malloy, Q.G.J., Travis, S.A., Bobmanuel, L.M., Lefer, B.L., Flynn, J.H., 2013. Role of atmospheric ammonia in particulate matter formation in Houston during summertime. Atmospheric Environment, 77, 893-900.

Heald, C.L., Collett Jr., J.L., Lee, T., Benedict, K.B., Schwandner, F.M., Li, Y., Clarisse, L., Hurtmans, D.R., Van Damme, M., Clerbaux, C., Coheur, P.-F., Philip, S., Martin, R.V., Pye, H.O.T., 2012. Atmospheric ammonia and particulate inorganic nitrogen over the United States. Atmospheric Chemistry and Physics 12, 10295-10312.

Horvath, H., 1992. Effects on visibility, weather and climate, in: Atmospheric acidity: sources, consequences and abatement, edited by Radojevic, M. and Harrison, R. M., chapter 13, London: Elsevier Applied Science. 
Meng, Z.Y., Lin, W.L., Jiang, X.M., Yan, P., Wang, Y., Zhang, Y.M., Jia, X.F., Yu, X.L, 2011. Characteristics of atmospheric ammonia over Beijing, China. Atmospheric Chemistry and Physics, 11, 6139-6151

Mira-Salama, D., Van Dingenen, R., Gruening, C., Putaud, J.-P., Cavalli, F., Cavalli, P., Erdmann, N., Dell'Acqua, A., Dos Santos, S., Hjorth, J., Raes, F., Jensen, N.R., 2008. Using Föhn conditions to characterize urban and regional sources of particles. Atmospheric Research 90, 159-169.

Paulot, F., Jacob, D.J., 2014. Hidden cost of U.S. agricultural exports: Particulate matter from ammonia emissions. Environmental Science and Technology, 48, 903-908.

Phan, N.-T., Kim, K.-H., Shon, Z.-H., Jeon, E.-C., Jung, K., Kim, N.-J., 2013. Analysis of ammonia variation in the urban atmosphere. Atmospheric Environment 65, 177-185.

Schiferl, L.D., Heald, C.L., Nowak, J.B., Holloway, J.S., Neuman, J.A., Bahreini, R., Pollack, I.B., Ryerson, T.B., Wiedinmyer, C., Murphy, J.G., 2014. An investigation of ammonia and inorganic particulate matter in California during the CalNex campaign. Journal of Geophysical Research: Atmospheres, 119, 1883-1902.

Schlesinger, R.B., Cassee, F., 2003. Atmospheric secondary inorganic particulate matter: the toxicological perspective as a basis for health effects risk assessment. Inhalation Toxicology $15,197-235$.

Shen, J., Liu, X., Zhang, Y., Fangmeier, A., Goulding, K., Zhang, F., 2011. Atmospheric ammonia and particulate ammonium from agricultural sources in the North China Plain. Atmospheric Environment 45, 2011, 5033-5041

Suh, H.H., Allen, G.A., Koutrakis, P., Burton, R.M., 1995. Spatial variation in acidic sulphate and ammonia concentrations within metropolitan Philadelphia, J. Air Waste Manage. Assoc. 45, 442-452.

Sutton, M.A., Asman, W.A.H., Schjørring, J.K., 1994. Dry deposition of reduced nitrogen. Tellus 46B, 255-273.

Sutton, M.A., Reis, S., Baker, S.M.H., 2009. Atmospheric Ammonia. Detecting Emission Changes and Environmental Impacts. Springer, 464 pp.

Villena, I., Bejan, R., Kurtenbach, P., Wiesen, P., Kleffmann, J., 2012. Interferences of commercial $\mathrm{NO}_{2}$ instruments in the urban atmosphere and in a smog chamber. Atmospheric Measurement Techniques 5, 149-159.

Wang, S., Nan, J., Shi, C., Fu, Q., Gao, S., Wang, D., Cui, H., Saiz-Lopez, A., Zhou, B., 2015. Atmospheric ammonia and its impacts on regional air quality. Scientific Reports 5, 15842. over the megacity of Shanghai, China. Sci. Rep. 5, 15842; doi: 10.1038/srep15842 (2015).

Warner, J.X., Wei, Z., Strow, L.L., Dickerson, R.R., Nowak, J.B., 2016. The global tropospheric ammonia distribution as seen in the 13-year AIRS measurement record. Atmospheric Chemistry and Physics, 16, 5467-5479.

Warner, J.X., Dickerson, R.R., Wei, Z., Strow, L.L., Wang, Y., Liang, Q., 2017. Increased atmospheric ammonia over the world's major agricultural areas detected from space. Geophysical research letters 44(6), 2875-2884.

Zbieranowski, A.L., Aherne, J., 2013 Ambient concentrations of atmospheric ammonia, nitrogen dioxide and nitric acid in an intensive agricultural region., Atmospheric Environment 70, 289-299.

Zhang, L., Jacob, D.J., Knipping, E.M., Kumar, N., Munger, J.W., Carouge, C.C., van Donkelaar, A., Wang, Y.X., Chen, D., 2012. Nitrogen deposition to the United States: Distribution, sources, and processes. Atmospheric Chemistry and Physics, 12, 4539-4544. 


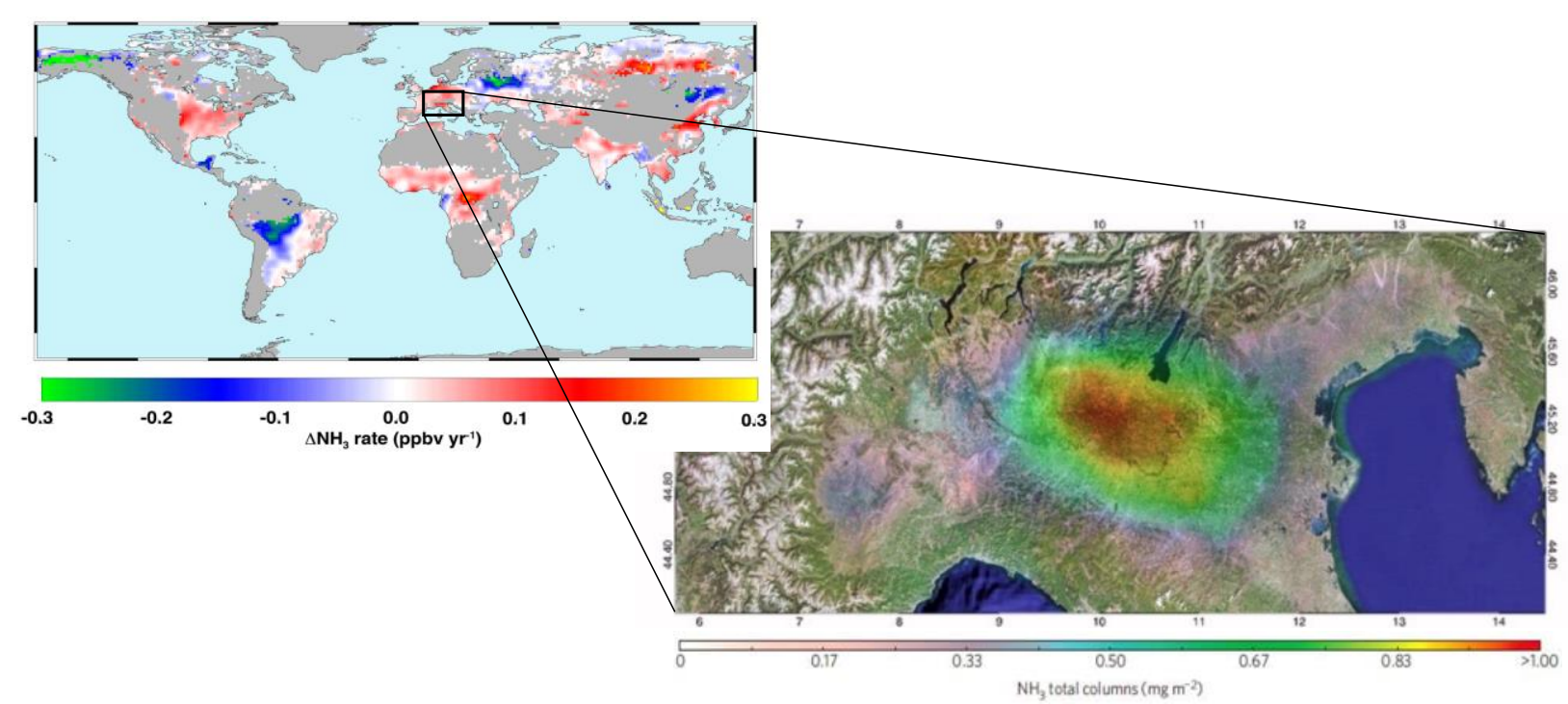

Figure 1 - Left: annual change of $\mathrm{NH}_{3}$ emission in 2002-2016 estimated from AIRS (Atmospheric Infrared Sounder, NASA) satellite measurements (Warner et al., 2017); right: average $\mathrm{NH}_{3}$ concentration over Northern Italy in 2008 from IASI (Infrared Atmospheric Sounding Interferometer, MetOp satellite) satellite measurements (Clarisse et al., 2009).

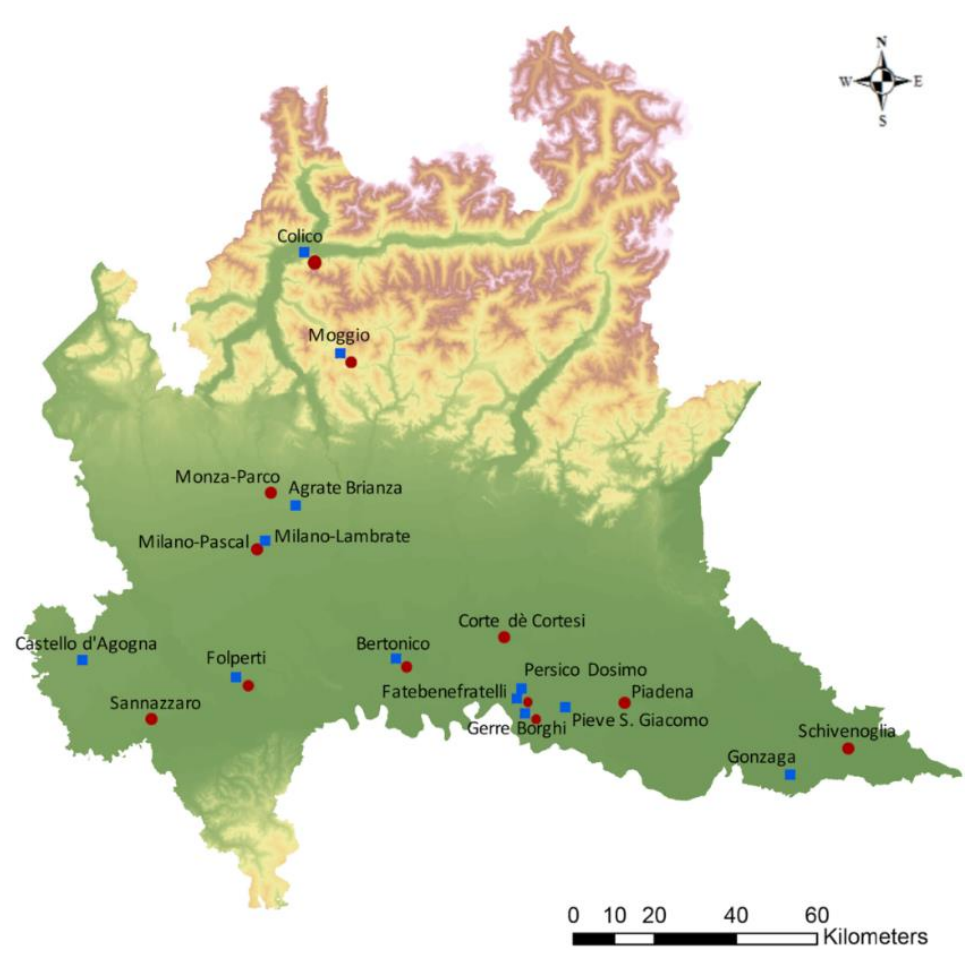

Figure $2-\mathrm{NH}_{3}$ monitoring sites (red circles) and meteorological stations for wind data (blue squares). 


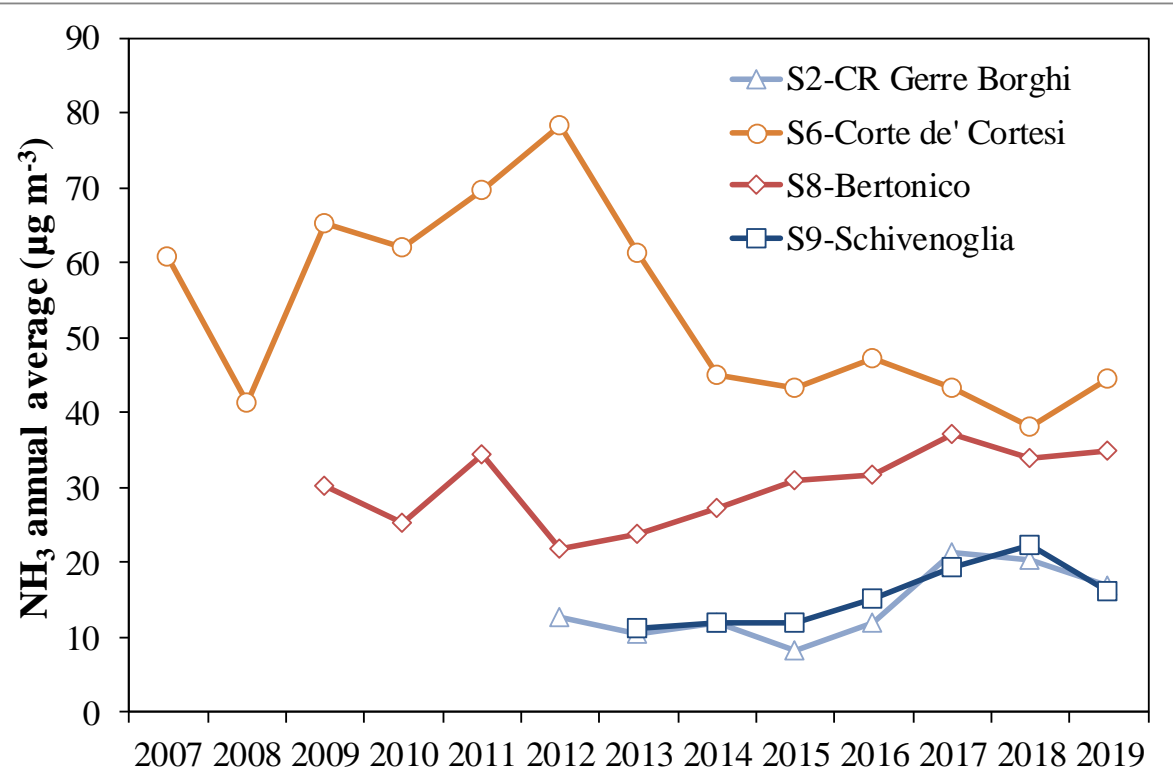

403

Figure 3 - Time patterns of $\mathrm{NH}_{3}$ annual average concentrations at the rural sites and the suburban $\mathrm{S} 2$ site.

406

407

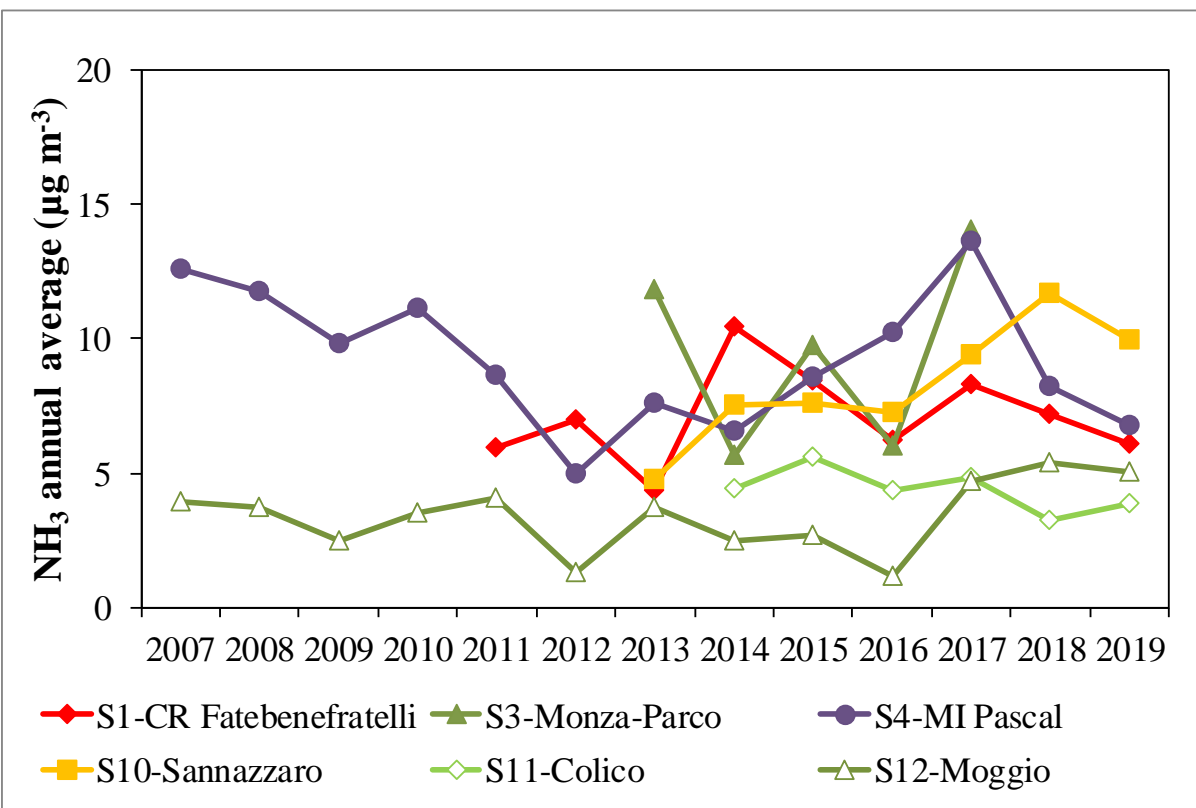

Figure 4 - Time patterns of $\mathrm{NH}_{3}$ annual average concentrations at the urban sites, site $\mathrm{S} 10$, and the mountain sites. 


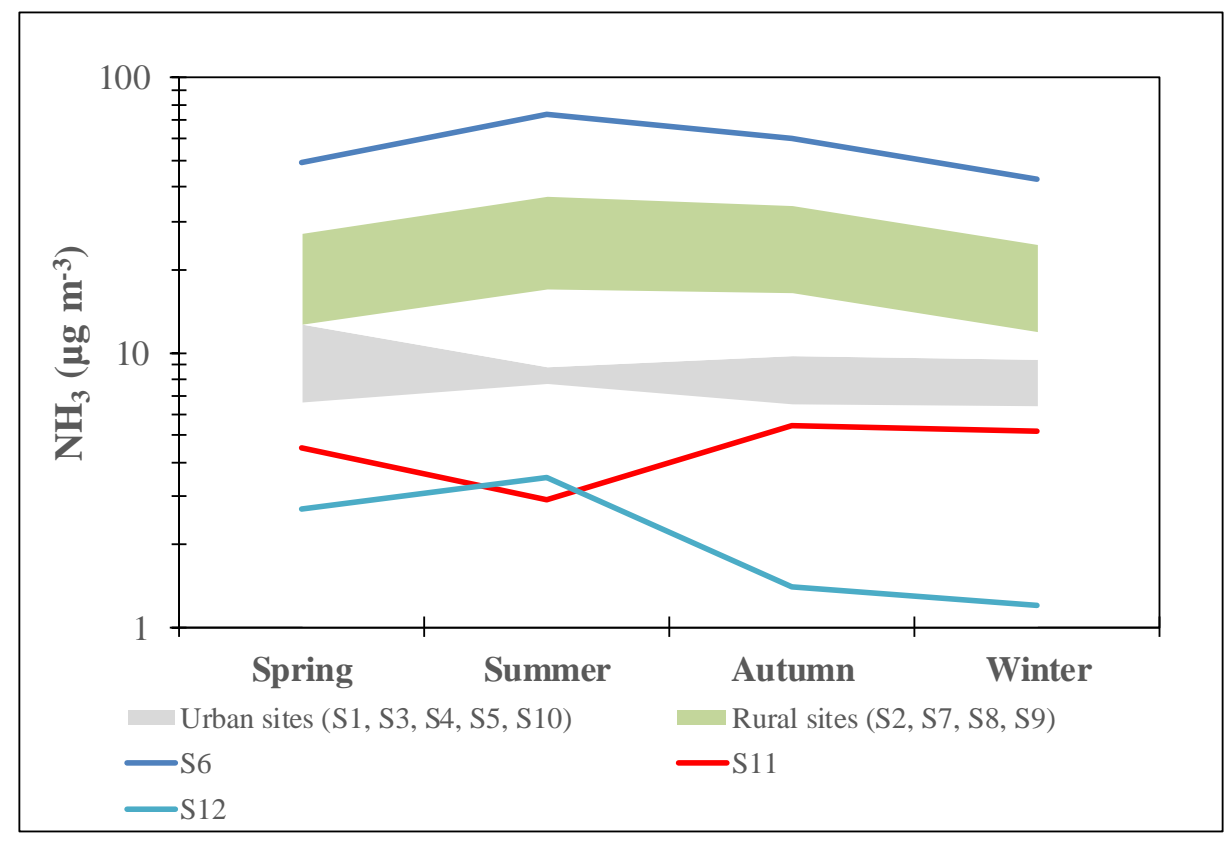

Figure 5 - Seasonally averaged $\mathrm{NH}_{3}$ concentrations at urban sites, rural site and at sites $\mathrm{S} 6$,

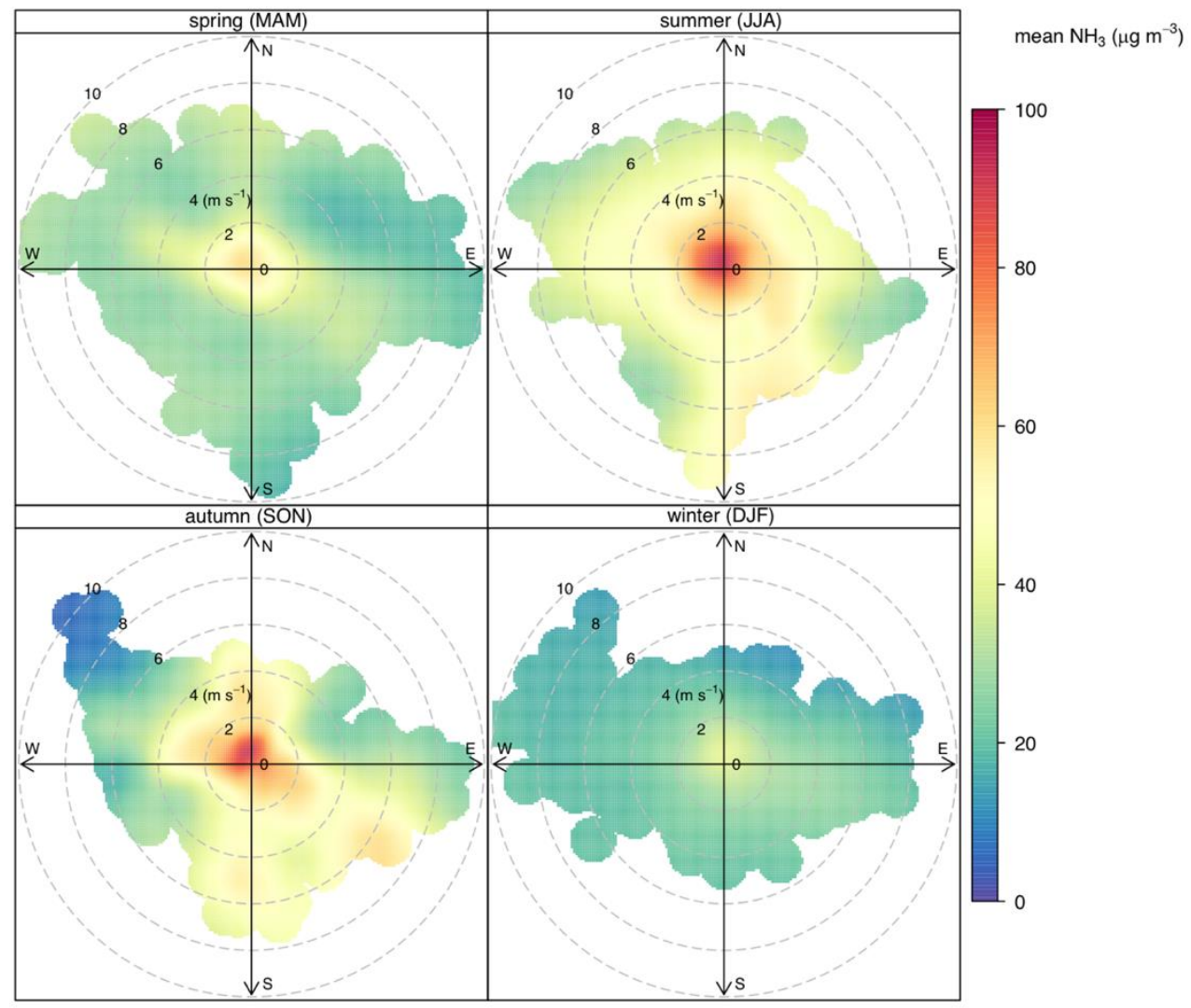

Figure 6 - Seasonal polar plots for $\mathrm{NH}_{3}$ hourly concentrations at rural site $\mathrm{S} 6$. 


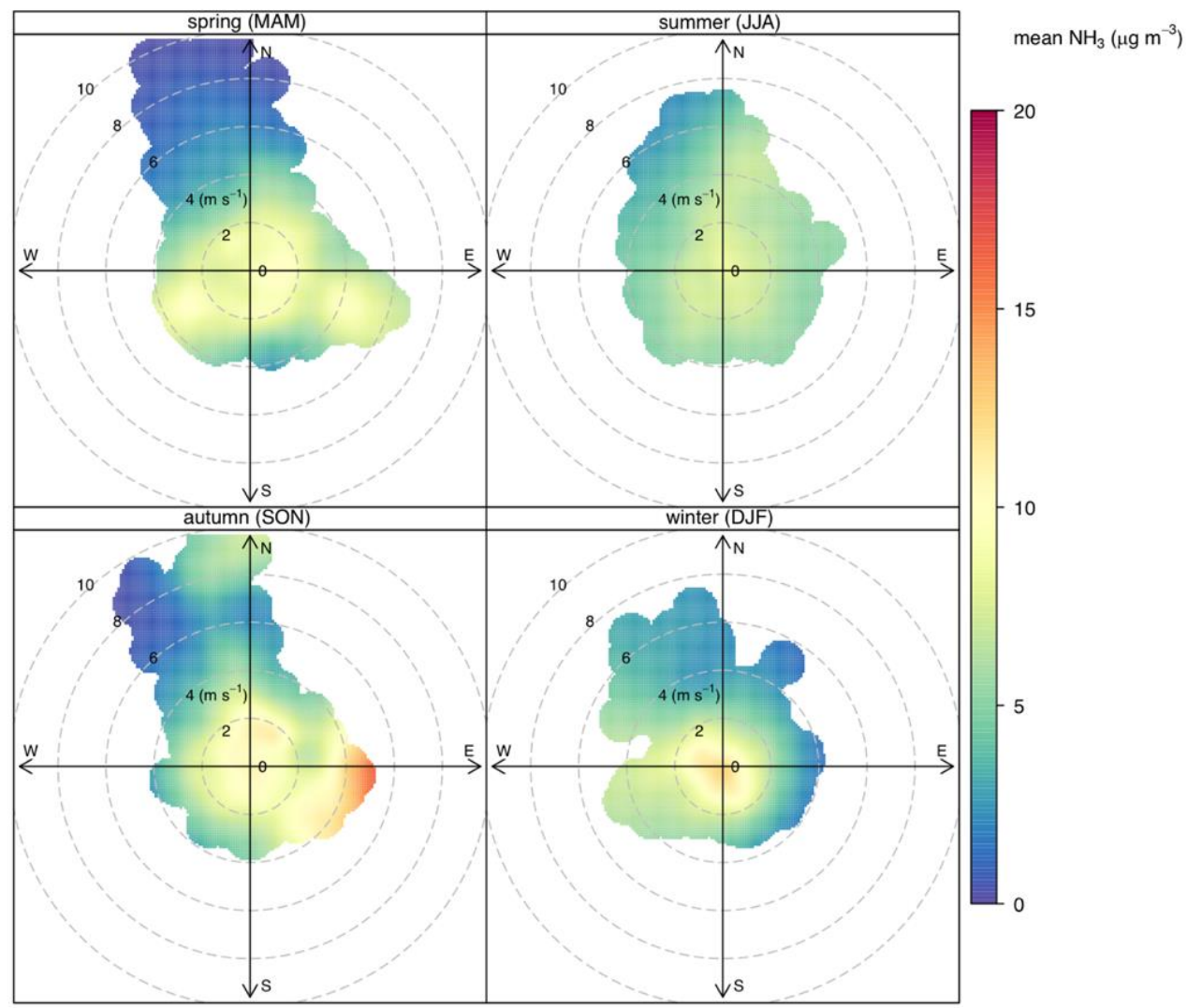

Figure 7 - Seasonal polar plots for $\mathrm{NH}_{3}$ hourly concentrations at urban site $\mathrm{S} 4$.

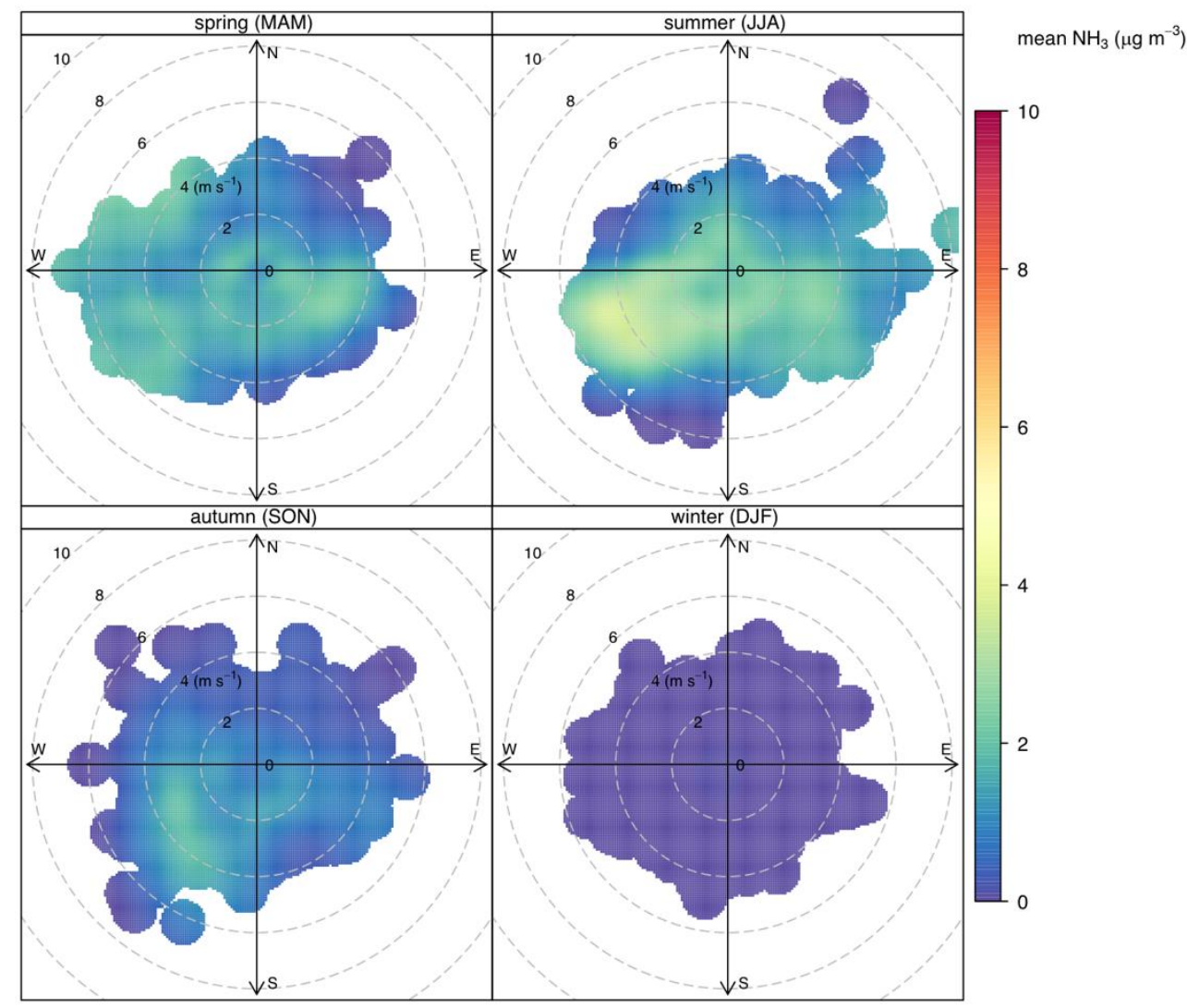

Figure 8 - Seasonal polar plots for $\mathrm{NH}_{3}$ hourly concentrations at mountain site $\mathrm{S} 12$. 


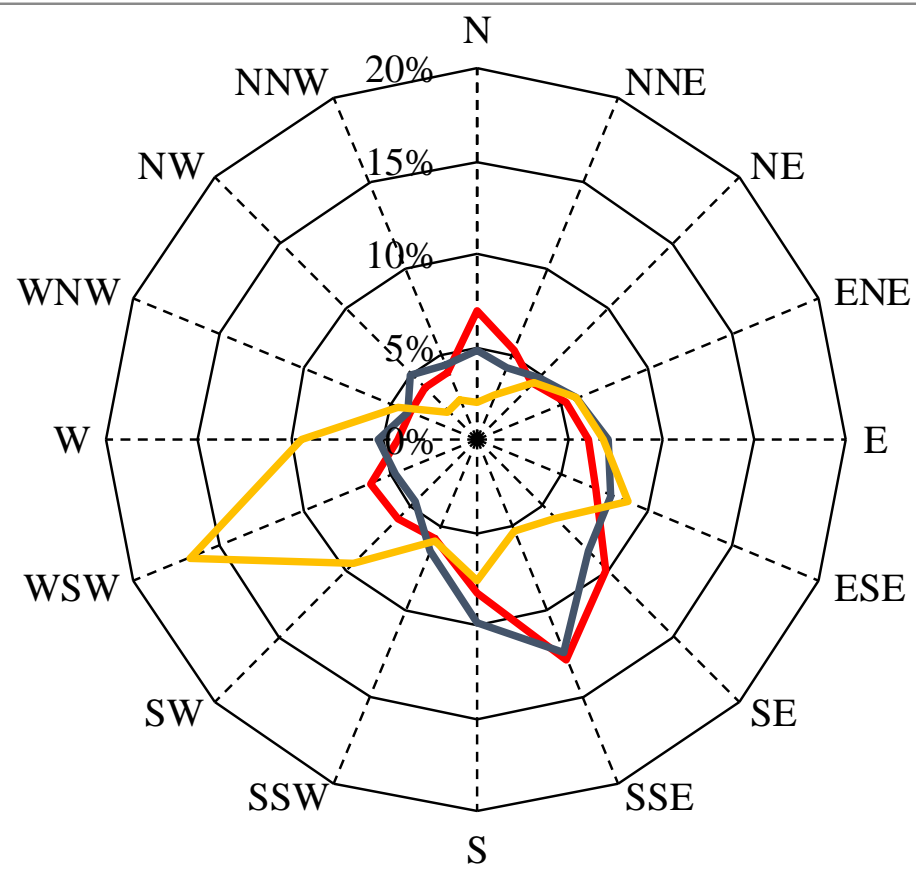

\section{$\longrightarrow$ S3-Monza Parco $\longrightarrow$ S4-MI Pascal $\longrightarrow$ S12-Moggio}

Figure 9 - Conditional wind roses for $\mathrm{NH}_{3}$ hourly concentration values higher than the $90^{\text {th }}$ 


\section{TABLES}

Table 1 - Mean and range (in brackets) for $\mathrm{NH}_{3}$ annual average concentration $\left(\mu \mathrm{g} \mathrm{m}^{-3}\right.$, at $20{ }^{\circ} \mathrm{C}$ 437 and $101.3 \mathrm{kPa}$ ) in Lombardy.

\begin{tabular}{|c|c|c|c|c|}
\hline \multirow{4}{*}{ Area } & Monitoring site & $\begin{array}{c}\text { Altitude } \\
(\mathbf{m} \text { a.s.l.) }\end{array}$ & Dataset & NH3 annual average \\
\hline \multirow{5}{*}{ Urban } & S1-CR Fatebenefratelli & 43 & $2011-2019$ & $7.1(4.4-10.7)$ \\
\cline { 2 - 5 } & S2-CR Gerre Borghi & 36 & $2012-2019$ & $14.2(8.2-21.3)$ \\
\cline { 2 - 5 } & S3-Monza Parco & 181 & $2013-2017$ & $9.5(6.0-13.4)$ \\
\cline { 2 - 5 } & S4-MI Pascal & 122 & $2007-2011$ & $9.6(6.5-12.6)$ \\
\cline { 2 - 5 } & S5-PV Folperti & 77 & $2013-2019$ & $10.3(8.1-13.3)$ \\
\hline \multirow{4}{*}{ Rural } & S6-Corte de' Cortesi & 57 & $2007-2019$ & $53.1(38.3-81.7)$ \\
\cline { 2 - 5 } & S7-Piadena & 30 & $2013-2014$ & $20.6(17.7-23.5)$ \\
\cline { 2 - 5 } & S8-Bertonico & 65 & $2009-2019$ & $30.1(21.9-35.8)$ \\
\cline { 2 - 5 } & S9-Schivenoglia & 12 & $2013-2019$ & $16.2(11.3-22.3)$ \\
\cline { 2 - 5 } & S10-Sannazzaro & 87 & $2014-2019$ & $8.4(7.4-9.9)$ \\
\hline \multirow{7}{*}{ Mountain } & S11-Colico & 229 & $2013-2019$ & $4.4(3.2-5.8)$ \\
\cline { 2 - 5 } & S12-Moggio & 1194 & $2007-2019$ & $3.4(1.1-5.1)$ \\
\hline
\end{tabular}

Table 2 - Mean values for $\mathrm{NH}_{3}$ seasonal average concentration $\left(\mu \mathrm{g} \mathrm{m}^{-3}\right.$, at $20{ }^{\circ} \mathrm{C}$ and $\left.101.3 \mathrm{kPa}\right)$ 441

$$
\text { in Lombardy. }
$$

\begin{tabular}{|c|c|c|c|c|c|c|c|c|c|c|c|c|}
\hline \multirow{2}{*}{ Season } & \multicolumn{4}{|c|}{ Urban } & \multicolumn{5}{c|}{ Rural } & \multicolumn{2}{c|}{ Mountain } \\
\cline { 2 - 14 } & S1 & S2 & S3 & S4 & S5 & S6 & S7 & S8 & S9 & S10 & S11 & S12 \\
\hline Spring & 7.5 & 12.7 & 12.7 & 11.4 & 8.7 & 45.3 & 20.9 & 27.5 & 16.3 & 7.5 & 4.2 & 3.8 \\
\hline Summer & 8.8 & 17.1 & 8.4 & 8.8 & 8.7 & 70.1 & 20.1 & 32.4 & 16.4 & 7.7 & 2.7 & 4.0 \\
\hline Autumn & 7.1 & 16.4 & 9.5 & 9.7 & 6.5 & 55.4 & 26.1 & 32.5 & 14.8 & 9.4 & 4.5 & 2.7 \\
\hline Winter & 6.4 & 11.9 & 9.3 & 8.2 & 8.4 & 39.3 & 16.6 & 28.1 & 15.6 & 9.4 & 5.5 & 2.1 \\
\hline
\end{tabular}


444

445

446

447

448

\section{SUPPLEMENTARY MATERIALS}

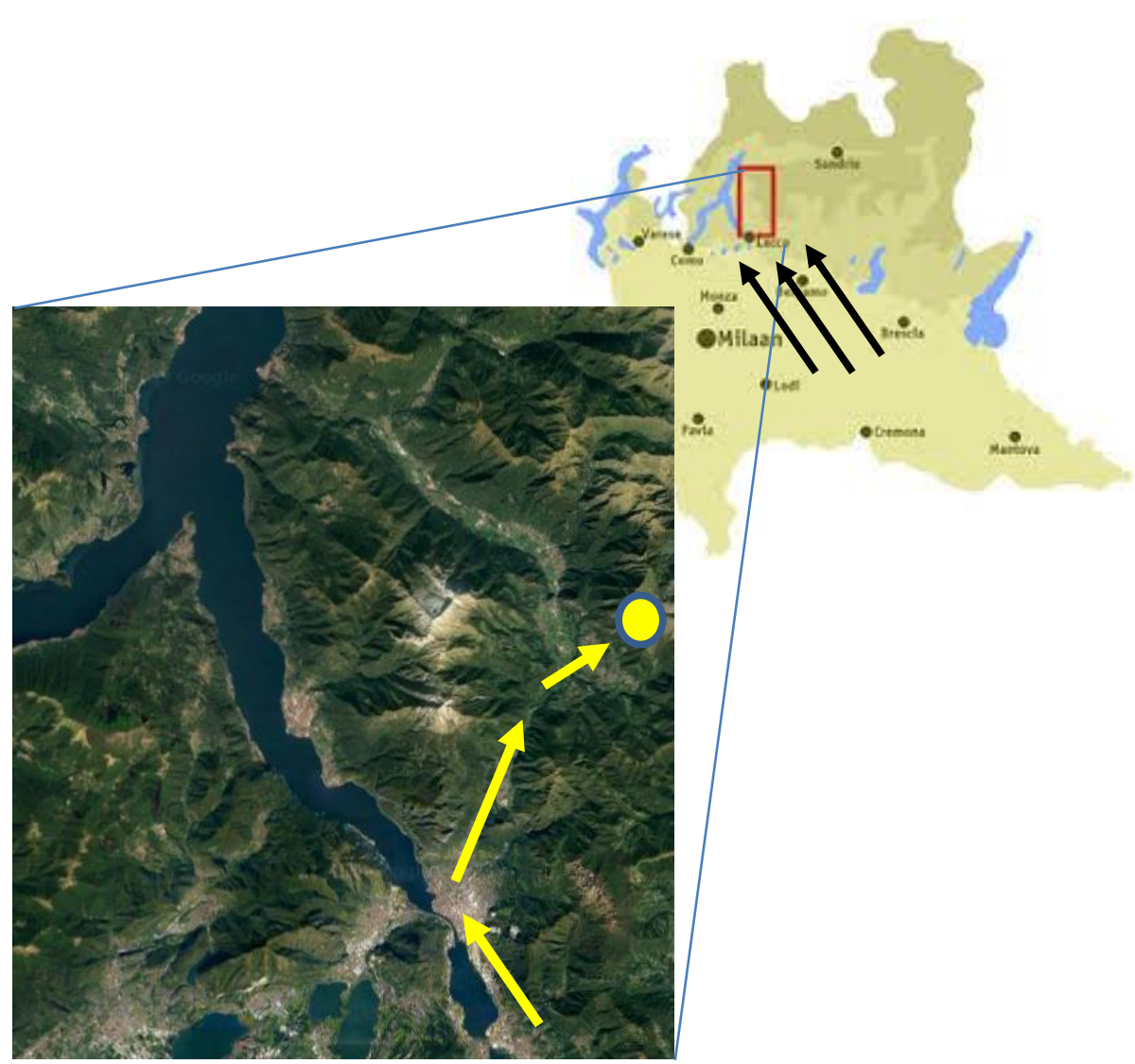

Figure 1 - Location of mountain site S12-Moggio and channelled path of air masses generated by summer breezes 